\title{
Development and characterization of novel ZnO-loaded electrospun membranes for periodontal regeneration
}

\author{
Eliseu A. Münchow ${ }^{a, b}$, Maria Tereza P. Albuquerque ${ }^{a, c}$, Bianca Zero $^{a}$, \\ Krzysztof Kamocki ${ }^{a}$, Evandro Piva ${ }^{b}$, Richard L. Gregory ${ }^{d}$, \\ Marco C. Bottino ${ }^{a, *}$ \\ a Department of Restorative Dentistry, Division of Dental Biomaterials, Indiana University School of Dentistry \\ (IUSD), Indianapolis, IN 46202, USA \\ b Department of Operative Dentistry, Federal University of Pelotas (UFPEL), School of Dentistry, Pelotas, RS \\ 96015-560, Brazil \\ c Graduate Program in Restorative Dentistry, Universidade Estadual Paulista, São José dos Campos Dental School, \\ São José dos Campos, São Paulo 12245-000, Brazil \\ d Department of Oral Biology, IUSD, Indianapolis, IN 46202, USA
}

\section{A R T I C L E I N F O}

\section{Article history:}

Received 21 January 2015

Received in revised form

16 April 2015

Accepted 1 June 2015

Keywords:

Electrospinning

Zinc oxide

Oral bacteria

Periodontal regeneration

Periodontitis

Membranes

\begin{abstract}
A B S T R A C T
Objectives. This study reports on the synthesis, materials characterization, antimicrobial capacity, and cytocompatibility of novel ZnO-loaded membranes for guided tissue/bone regeneration (GTR/GBR).

Methods. Poly( $\varepsilon$-caprolactone) (PCL) and PCL/gelatin (PCL/GEL) were dissolved in hexafluoropropanol and loaded with $\mathrm{ZnO}$ at distinct concentrations: 0 (control), 5, 15, and $30 \mathrm{wt} . \%$. Electrospinning was performed using optimized parameters and the fibers were characterized via scanning and transmission electron microscopies (SEM/TEM), energy dispersive $\mathrm{X}$-ray spectroscopy (EDS), Fourier transform infrared spectroscopy (FTIR), contact angle (CA), mechanical testing, antimicrobial activity against periodontopathogens, and cytotoxicity test using human dental pulp stem cells (hDPSCs). Data were analyzed using ANOVA and Tukey $(\alpha=5 \%)$.

Results. ZnO nanoparticles were successfully incorporated into the overall submicron fibers, which showed fairly good morphology and microstructure. Upon ZnO nanoparticles' incorporation, the PCL and PCL/GEL fibers became thicker and thinner, respectively. All GEL-containing membranes showed lower CA than the PCL-based membranes, which were highly hydrophobic. Overall, the mechanical properties of the membranes were reduced upon $\mathrm{ZnO}$ incorporation, except for PCL-based membranes containing $\mathrm{ZnO}$ at the $30 \mathrm{wt} . \%$ concentration. The presence of GEL enhanced the stretching ability of membranes under wet conditions. All $\mathrm{ZnO}$-containing membranes displayed antibacterial activity against the bacteria tested, which was generally more pronounced with increased $\mathrm{ZnO}$ content. All membranes synthesized in this study demonstrated satisfactory cytocompatibility, although the presence of $30 \mathrm{wt} . \% \mathrm{ZnO}$ led to decreased viability.
\end{abstract}

\footnotetext{
* Corresponding author at: Indiana University School of Dentistry, Department of Restorative Dentistry, Division of Dental Biomaterials, 1121 W. Michigan St., (DS112A) Indianapolis, IN 46202, USA. Tel.: +1 317274 3725; fax: +1 3172787462.

E-mail address: mbottino@iu.edu (M.C. Bottino).
} 
Significance. Collectively, this study suggests that PCL- and PCL/GEL-based membranes containing a low content of $\mathrm{ZnO}$ nanoparticles can potentially function as a biologically safe antimicrobial GTR/GBR membrane.

() 2015 Academy of Dental Materials. Published by Elsevier Ltd. All rights reserved.

\section{Introduction}

Periodontitis is a very prevalent (ca. $\sim 50 \%$ of the adult population) and aggressive dental pathology affecting both the gingiva and anchoring tissues of the tooth [1]. It is a bacterialmediated inflammatory process, and if not treated, it may progressively destroy periodontal tissues, eventually resulting in tooth loss [2]. A recent systematic review confirmed that severe periodontitis has increased in the past two decades, and a predictable increasing burden of the disease can be expected, since life expectancy among the world population is continuously growing [3].

The traditional clinical treatment of periodontitis consists of surgical procedures and mechanical debridement (i.e. scaling and root planing), which allows healing of periodontal pockets/defects [4,5]. Moreover, systemic and/or local antibiotic therapy may also be indicated in order to combat the infection or re-colonization of periodontopathogens [4-6]. Nonetheless, depending on the size of the pocket/inflamed site, the complete regeneration of periodontal tissues remains a difficult clinical task [4]. In this way, regenerative approaches, such as the use of bioresorbable or non-resorbable barrier membranes employed in so-called guided tissue/bone regeneration (GTR/GBR) strategies, as well as emerging technologies (e.g. cell-based and gene therapies, the use of bone anabolics, and laser treatments, among others) have been investigated in terms of their clinical potential in periodontal tissue regeneration $[4,7,8]$. Among the aforementioned approaches, GTR/GBR membranes present the unique characteristic of resembling the extracellular matrix (ECM), thus facilitating cell adhesion, proliferation, and the differentiation of new tissues [4]. Furthermore, GTR/GBR membranes can be synthesized using a variety of natural and/or synthetic polymers, and depending on processing conditions, bioactive (e.g. antimicrobials) fibers on the nano- and micro-scale range can be fabricated [4,6,9-12].

Despite the fairly significant clinical success achieved with the use of membranes in GTR/GBR strategies, tissue regeneration is strongly dependent on the absence of infection, and therefore, the proper maintenance of a bacteria-free environment [4]. To that end, several controlledrelease systems, such as Atridox ${ }^{\circledR}$ (doxycycline-based) and PerioChip ${ }^{\circledR}$ (chlorhexidine-based), have been thoroughly used to locally deliver antimicrobial agents to the periodontal pocket, resulting in positive clinical effects [13,14]. More recently, antimicrobial agents have been incorporated into GTR/GBR membranes, endowing to them antibacterial activity $[6,15]$. Notwithstanding, it is well recognized that antibiotics may produce some important side-effects, mainly those related to bacterial strain resistance, which is a current global concern, since bacteria are becoming resistant to several antibiotic therapies [4,6]. Therefore, the development of biomaterials for GTR/GBR applications based on alternative antibacterial agents rather than antibiotics is paramount to translate safer regenerative technologies into clinical practice.

Inorganic ions and metallic oxides have extensively demonstrated antibacterial properties [16-19]. Silver is the most effective antibacterial metal at low concentrations and against both gram-positive $(\mathrm{G}+)$ and gram-negative $(\mathrm{G}-)$ bacteria. Meanwhile, several other metal oxides (e.g. copper, magnesium, calcium, titanium, and zinc) have also displayed important antibacterial activity against a wide variety of microorganisms. Zinc oxide (ZnO), for example, is one of the few zinc-based compounds listed as being generally recognized as a safe (GRAS) material by the Food and Drug Administration (FDA) [20]. Even though the mechanism of action is still vaguely understood, ZnO has been successfully used as an antibacterial agent in food packaging [21], restorative dental materials [22], wound dressings [23], and in tissue engineering applications [24]. Indeed, electrospun polymer-based scaffolds/membranes loaded with $\mathrm{ZnO}$ have recently displayed not only antibacterial properties [25], but also enhanced cell proliferation/wound healing [26]. It is also important to note that the antibacterial activity of these $\mathrm{ZnO}$ loaded membranes was found to be dose-dependent ( $\geq 5 \mathrm{wt} . \%$ ) [25]. Nonetheless, the earlier study tested the ZnO-scaffolds only on Staphylococcus aureus (G+) and Escherichia coli (G-), thus further highlighting the need to investigate their potential against periodontopathogens based on their application as GTR/GBR membranes.

It is well-established that degradability is one of the most important aspects involved in the clinical success of bioresorbable GTR/GBR membranes [4]. Indeed, it is expected that the membrane would be completely resorbed after treatment is completed, thus eliminating an additional surgical procedure for its removal from the regenerated site [4]. The degradability rate of GTR/GBR membranes strongly depends on the type of polymer system used. Poly( $\varepsilon$-caprolactone) (PCL) is a synthetic polymer with known degradability and hydrophobic characteristics [27], and considering the latter property influences the former, with highly hydrophobic systems displaying lower degradability, PCL usually presents a moderate degradation rate. Recent research has utilized the strategy of blending natural polymers, such as collagen or gelatin, with PCL to grant enhanced degradability and hydrophilicity [28-30], as well as better cell-membrane response [31].

In this study, we tested the influence of ZnO nanoparticles and gelatin on the physico-chemical and mechanical properties of PCL-based electrospun membranes. Furthermore, we report for the first time on the antibacterial activity and cytocompatibility of these membranes' targeting 
a specific application in periodontal tissue regeneration by careful antimicrobial and cell compatibility evaluations against periodontopathogens and dental pulp stem cells, respectively.

\section{Materials and methods}

\subsection{Materials}

Poly( $\varepsilon$-caprolactone) pellets (PCL, $M_{\mathrm{w}}=80,000$ ), gelatine type B from bovine skin ( 225 bloom, $\left.M_{\mathrm{W}}=50,000\right)$, 1,1,1,3,3,3hexafluoro-2-propanol (HFP), and zinc oxide nanoparticles $(\mathrm{ZnO},<100 \mathrm{~nm}$ particle size) were all purchased from Sigma-Aldrich (St. Louis, MO, USA) and used as-received. Phosphate-buffered saline solution (PBS, 1\%) was prepared by mixing PBS tablets (MP Biomedicals, Santa Ana, CA, USA) and distilled water. The plastic syringes $(5 \mathrm{~mL})$ and $27 \mathrm{G}$ dispensing needles were obtained from Becton, Dickson and Company (Franklin Lakes, NJ, USA) and CML Supply (Lexington, KY, USA), respectively.

\subsection{Synthesis of PCL and PCL/Gelatin membranes loaded with $\mathrm{ZnO}$ nanoparticles}

The electrospinning system used in this work consisted of a high-voltage source (ES50P-10W/DAM, Gamma High-Voltage Research Inc., Ormond Beach, FL, USA), a syringe pump (Legato 200, KD Scientific Apparatus, Holliston, MA, USA), and a grounded stainless steel collecting drum connected to a highspeed mechanical stirrer (BDC6015, Caframo, Wiarton, ON, Canada), and was described in detail elsewhere [6,32,33]. Processing parameters, including solution concentration, field strength, and flow rate were optimized for the distinct polymer systems to obtain defect-free fibrous membranes. Two stock polymer solutions were prepared in HFP; namely, pure PCL and a PCL/gelatin blend (PCL/GEL, ratio of $1: 1, \mathrm{w} / \mathrm{w})$. Briefly, the polymers were dissolved in HFP to produce a $10 \mathrm{wt}$ \% solution (100 $\left.\mathrm{mg} \mathrm{mL}^{-1}\right)$ and were stirred overnight. Next, ZnO nanoparticles were added at different concentrations $(0,5,15$, and $30 \mathrm{wt} . \%$, relative to the total polymer weight); the mixtures were stirred for $24 \mathrm{~h}$ and then sonicated for $90 \mathrm{~min}$ before electrospinning to improve nanoparticle dispersion [7]. Each solution was then loaded into the plastic syringe fitted with the $27 \mathrm{G}$ metallic blunt-tip and electrospun using the following parameters: rotating mandrel (120 rpm of speed), fixed spinning distance of $18 \mathrm{~cm}$, flow rate of $1.5 \mathrm{~mL} / \mathrm{h}$, and different electric voltages, depending on the solution, as determined by an optimization process that involved experiments conducted on each variable. The obtained mats (hereafter referred to as membranes), i.e. pure PCL, PCL/GEL, and the ones containing $\mathrm{ZnO}$ nanoparticles, were collected at room temperature (RT) and then dried under vacuum for at least $48 \mathrm{~h}$ to complete removal of any remaining solvent $[7,32]$.

\subsection{Morphological (SEM/TEM) and chemical (EDS/FTIR) characterizations of the fibers}

The electrospun membranes were observed under a fieldemission scanning electron microscope (FE-SEM, Model
JSM-6701F, JEOL, Tokyo, Japan) to evaluate the morphology and overall fiber architecture. In brief, samples taken from the different electrospun membranes were mounted on an $\mathrm{Al}$ stub and sputter-coated with $\mathrm{Au}-\mathrm{Pd}$ prior to imaging. Image J software (National Institutes of Health, Bethesda, MD, USA) was used to calculate the diameter of 50 single-fibers per image obtained from the FE-SEM analyses (3 images/group) at the same magnification $(5000 \times)$; the fiber diameter was then averaged and reported as mean $\pm \mathrm{SD}[7,32]$. Energy dispersive X-ray spectroscopy (EDX) was performed under FE-SEM to semiquantitatively analyse the chemical composition of the fibers. Transmission electron microscopy (TEM, Model JEM-2010, JEOL) was also carried out to investigate the ZnO nanoparticles' incorporation into the polymer fibers. Fourier transform infrared spectroscopy (FTIR) was done in the attenuated total reflection mode for the PCL, PCL/GEL, and membranes containing ZnO nanoparticles (ATR/FTIR-4100, JASCO, Easton, MD, USA), over the range of $700-4000 \mathrm{~cm}^{-1}$ at a resolution of $4 \mathrm{~cm}^{-1}$ to investigate the chemical characteristics of the membranes and $\mathrm{ZnO}$ incorporation [7,32].

\subsection{Contact angle (CA)}

The PCL and PCL/GEL solutions loaded or not with the distinct concentration of $\mathrm{ZnO}$ were electrospun into fibers using the aforementioned electrospinning parameters over microscope glass coverslips (Fisherbrand, Fisher Scientific, Loughborough, UK) mounted on the rotating mandrel $(n=10)$. Next, the surface CA of the membranes was measured using a goniometer (Model PG-2, Gardco, Pompano Beach, FL, USA) by dropping three consecutive drops of distilled water $(\sim 5 \mu \mathrm{L})$ per sample. The measured angles were then averaged.

\subsection{Mechanical properties}

The mechanical properties (i.e. tensile strength, Young's modulus, and elongation at break) of all the synthesized electrospun membranes were evaluated by uni-axial tensile testing (expert 5601, ADMET, Norwood, MA, USA) [32]. Rectangular samples $(15 \mathrm{~mm} \times 3 \mathrm{~mm})$ were tested $(n=8)$ under both dry (immediate testing without storage) or wet (tested after storage in PBS solution for $24 \mathrm{~h}$ ) conditions at a crosshead speed of $1 \mathrm{~mm} \mathrm{~min}^{-1}$. The specimen thickness was determined by measuring with calipers at three locations. Mechanical data were obtained from the stress-strain curves of each sample and expressed in MPa. The results are reported as mean \pm standard deviation (SD).

\subsection{Antimicrobial activity}

The antibacterial activity of the processed fibrous membranes was evaluated against known periodontopathogens, i.e. Porphyromonas gingivalis (Pg) (ATCC 33277) and Fusobacterium nucleatum (Fn) (ATCC 25586) using agar diffusion assays ( $n=3$ /group/bacteria) [33]. Bacteria were cultivated in Brain Heart Infusion (BHI) broth supplemented with $5 \mathrm{~g}$ yeast extract/L and $5 \%$ (v/v) vitamin K+ hemin (BHI-YE; Becton, Dickinson and Company) at $37^{\circ} \mathrm{C}$ in an anaerobic GasPak jar for $24 \mathrm{~h}$ [33]. Before testing, the minimum inhibitory concentration (MIC) of $\mathrm{ZnO}$ was determined using suspensions of $\mathrm{ZnO}$ 
nanoparticles in PBS at the following concentrations: 100, 250, $500,1,000,2,500,5,000$, and $10,000 \mu \mathrm{g} / \mathrm{mL}$. In brief, $10 \mu \mathrm{L}$ of each suspension was dropped on cultured blood agar plates containing the bacterial lawns, and the inhibition zones (in $\mathrm{mm}$ ) were measured after 5 days of incubation [33]. For the antibacterial activity of the membranes, disk-shaped samples (5-mm in diameter) were prepared and sterilized through ultraviolet (UV) irradiation for $1 \mathrm{~h}$ (30 min each side), before placing on the cultured blood agar plates as previously indicated [33,34]. The inhibition zone (in $\mathrm{mm}$ ) of each sample was measured after 5 days of incubation.

\subsection{Cytotoxicity test}

The guidelines provided by the International Standards Organization/ISO [35] were followed in order to detect toxicity levels of the electrospun membranes [34]. Human dental pulp stem cells (hDPSCs, AllCells LLC, Alameda, CA, USA) obtained from permanent third molars were cultured in low glucose Dulbecco's Modified Eagle's Medium (DMEM, GIBCO, Invitrogen, Grand Island, NY, USA) supplemented with $10 \%$ FBS (Hyclone Laboratories Inc., Logan, UT, USA) and 1\% penicillin-streptomycin (Sigma) in a humidifier incubator at $37^{\circ} \mathrm{C}$, with $5 \% \mathrm{CO}_{2}$ [34]. All the processed membranes were carefully cut into squares $(15 \mathrm{~mm} \times 15 \mathrm{~mm})$ and sterilized under UV light ( $30 \mathrm{~min}$ each side) and by soaking in $70 \%$ ethanol for $30 \mathrm{~min}$, followed by washing $(5 \mathrm{~min})$ twice in sterile PBS before testing [34]. Next, sterile samples (surface ratio $=1 \mathrm{~cm}^{2} / \mathrm{mL}$ of medium) were incubated in DMEM for $48 \mathrm{~h}$ at $37^{\circ} \mathrm{C}$ under a $5 \% \mathrm{CO}_{2}$ humidified atmosphere in order to produce extracts from each membrane [34]. Extracts of sterile ultra-high molecular weight polyethylene (UHMWPE) were similarly obtained (negative control). Supernatants were then filtered through a membrane (Millipore ${ }^{\circledR}$ ), and serial dilutions $(100,50,25,12.5$, and $6.25 \mathrm{vol} . \%)$ were prepared from the extracts $[34,36]$. Dilutions were also performed for the positive control (i.e. 0.3 vol.\% phenol solution) $[34,36]$. hDPSCs at passage 9 were seeded at a density of $3 \times 10^{3} /$ well and allowed to adhere in the wells of 96 -well tissue culture microtiter plates. The media was replaced after $4 \mathrm{~h}$ by the corresponding extract concentrations, and negative and positive controls, which were dispensed into each well $(100 \mu \mathrm{L})$ [34]. Control columns of four wells were prepared with a medium without cells (blank), and a medium with cells but without the extract (100\% survival) [34-36]. The microplate was then incubated again and after $48 \mathrm{~h}, 20 \mu \mathrm{L}$ of CellTiter 96 AQueous One Solution Reagent (Promega Corporation, Madison, WI, USA) was added to the test wells and allowed to react for $2 \mathrm{~h}$ at $37^{\circ} \mathrm{C}$ in humidified $5 \% \mathrm{CO}_{2}$ atmosphere. Incorporated dye was measured by reading the absorbance at $490 \mathrm{~nm}$ in a microplate reader against a blank column [34-36].

\subsection{Statistical analysis}

The obtained data were statistically analysed (SigmaPlot version 12, Systat Software Inc., San Jose, CA, USA) using Analysis of Variance (One-Way for cytocompatibility test and Two-Way for all the other tests) and Tukey's test for multiple comparison $(\alpha=5 \%)$.

\section{Results}

\subsection{Morphological and chemical characterizations of the fibers}

The PCL- and PCL/GEL-based membranes presented, respectively, a heterogeneous (from 93 to $2,223 \mathrm{~nm}$ ) and homogeneous (from 56 to $1184 \mathrm{~nm}$ ) fiber diameter distribution (Fig. 1a). The presence of gelatine produced thicker fibers compared to those gelatine-free, although only in groups containing none or low content ( $5 \mathrm{wt} . \%$ ) of $\mathrm{ZnO}$. The incorporation of higher amounts of $\mathrm{ZnO}$ (higher than $15 \mathrm{wt} . \%$ ) resulted in rough fibers with distinct shape (e.g., swollen areas) and morphology, although the PCL membranes were more negatively affected than those constituted of gelatine (Fig. 2). As shown in the EDS analysis (Fig. 1b), ZnO nanoparticles were successfully incorporated into the membranes. The nanoparticles differed in shape, although most of them were rod-like and nano-sized (i.e. below $100 \mathrm{~nm}$, with an average size of $65 \mathrm{~nm}$ ) (Fig. 3). While the neat fibers were visually smooth (Fig. 4a), the nanocomposite fibers presented some swollen areas and several areas embedded with $\mathrm{ZnO}$ nanoparticles (Fig. 4b). Lastly, the FTIR analysis also revealed incorporation of $\mathrm{ZnO}$ into the membranes (Fig. 5) and gelatine into the PCL/GEL-based membranes (Fig. 5b). The presence of the peak located at $2357 \mathrm{~cm}^{-1}$ could be observed in the $\mathrm{ZnO}$ powder and also in the $\mathrm{ZnO}$ incorporated membranes, but not in the neat membranes. FTIR spectra showed some common peaks for all membranes located at 2944-2861 and $1721 \mathrm{~cm}^{-1}$, which corresponded, respectively, to the presence of the $\mathrm{C}-\mathrm{H}$ bond of saturated carbons and the ester-carbonyl group (-CO stretching) found in PCL [25]. In addition, three characteristic peaks confirmed the incorporation of gelatine into the PCL/GEL membranes: one located at $3297 \mathrm{~cm}^{-1}$ (amide-A), another at $1627 \mathrm{~cm}^{-1}$ (amideI), and the last at $1524 \mathrm{~cm}^{-1}$ (amide-II).

\subsection{Contact angle}

According to Fig. 6, all PCL-based membranes, regardless of the $\mathrm{ZnO}$ content $(p \geq 0.056)$, presented a hydrophobic surface (i.e. contact angle higher than $90^{\circ}$ ), showing poor wettability. By contrast, PCL/GEL membranes revealed excellent wettability/hydrophilicity, with CA ranging from $0^{\circ}$ to $42^{\circ}$. The PCL/GEL membranes containing 5 and $15 \mathrm{wt}$ \% of $\mathrm{ZnO}$ nanoparticles were more hydrophilic than the other gelatine-based membranes $(p<0.001)$.

\subsection{Mechanical properties}

The mechanical performance (e.g. tensile strength, Young's modulus, and elongation at break) of the synthesized membranes is presented in Fig. 7. The PCL membranes showed a soft nature with moderate flexibility regardless of the storage condition. The incorporation of $\mathrm{ZnO}$ reduced the mechanical properties, except the elongation at break, which was increased with the addition of $30 \mathrm{wt}$ \% of nanoparticles. The presence of gelatine improved rigidity of the membranes, but only under dry circumstances $(p \leq 0.002)$; conversely, storage in $\mathrm{PBS}$ resulted in a significant decrease in rigidity, although 


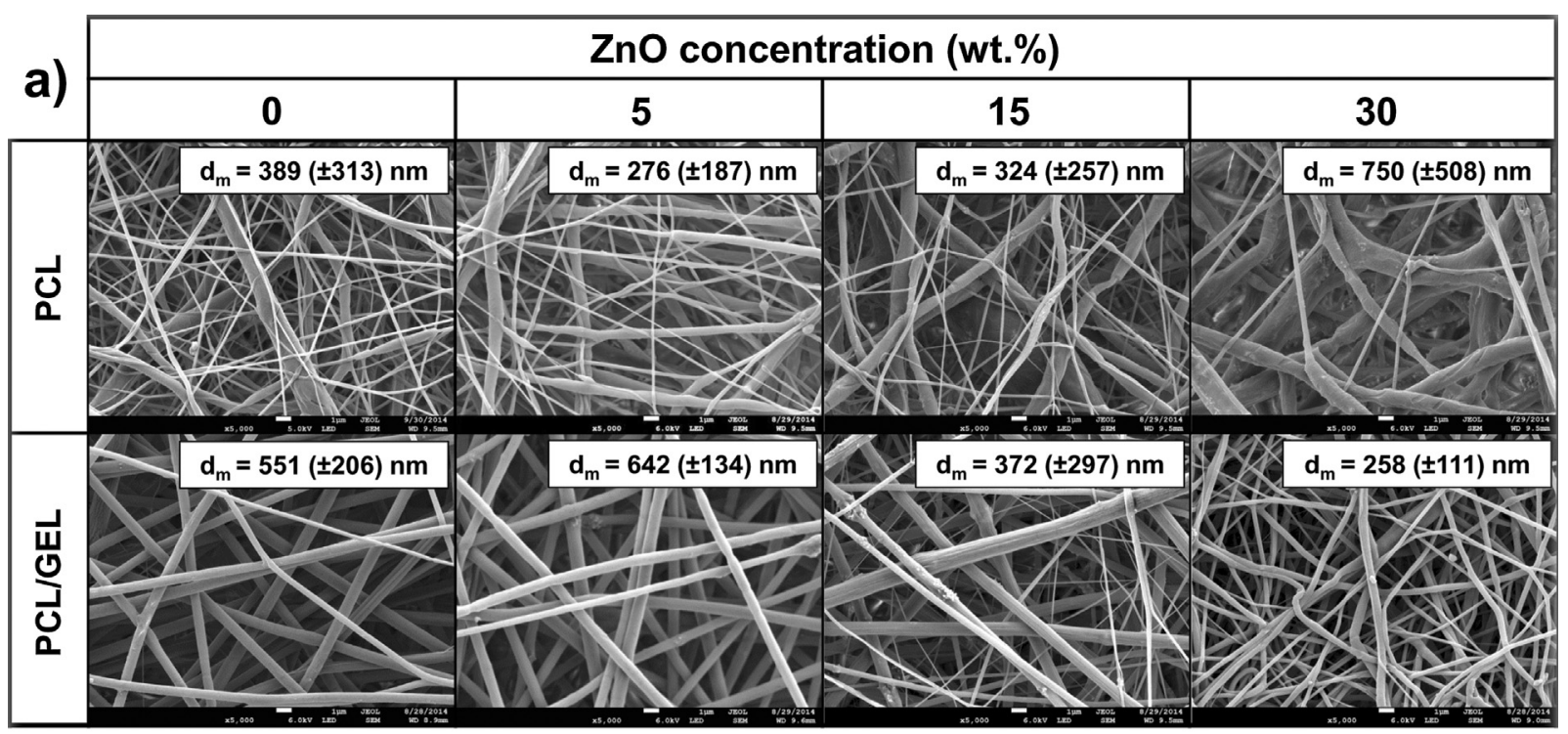

b)

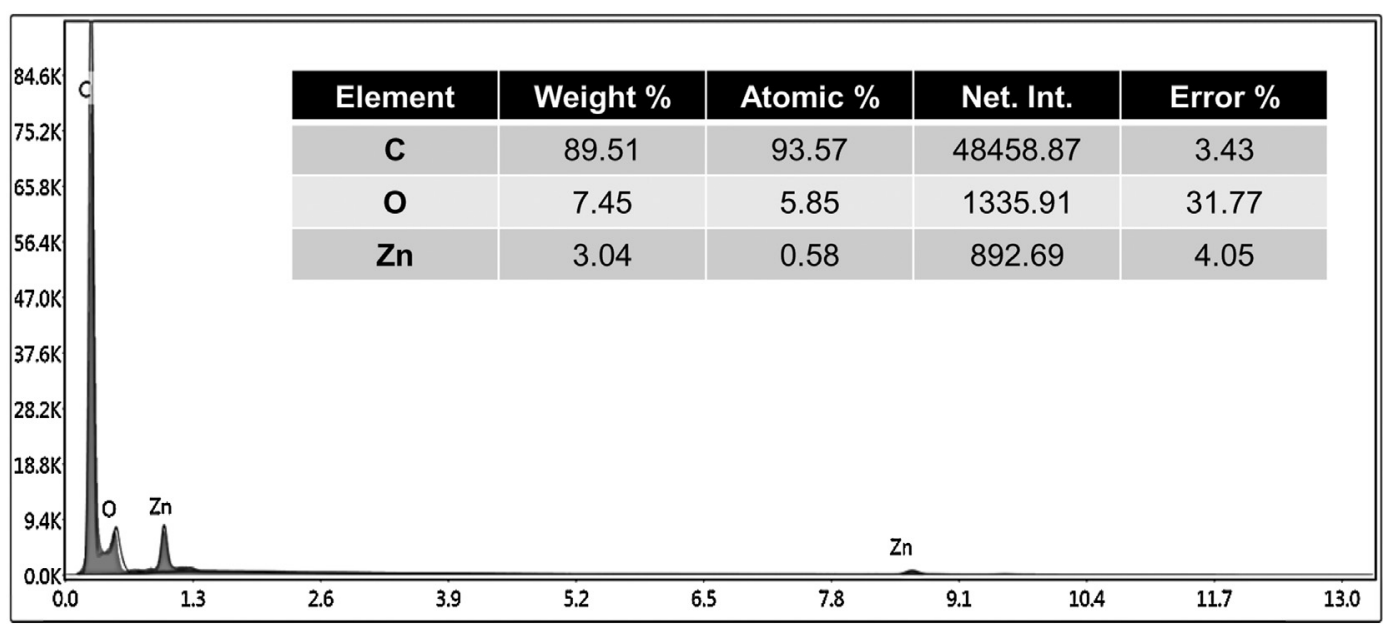

Lsec: 30.00 Cnts 0.000 keV Det: Octane Super Det

Fig. 1 - (a) Representative SEM micrographs for the PCL- and PCL/GEL-based membranes containing different concentrations of ZnO. Insets within the SEM micrographs show the mean fiber diameter $\left(d_{m}\right)$ and standard deviation ( $\left.\pm S D\right)$. (b) Representative EDS analysis of the PCL nanocomposite membrane containing $15 \mathrm{wt}$ \% of ZnO confirming the presence of ZnO nanoparticles within the fibers.

a substantial gain in flexibility could be observed: wet specimens of membranes containing $0,5,15$, and $30 \mathrm{wt} . \%$ of ZnO displayed, respectively, 3.4, 2.9, 2.7, and 4.3 times higher $(p<0.001)$ elongation at break than the specimens stored dry.

\subsection{Antibacterial activity}

Results of the MIC of ZnO nanoparticles are shown in Table 1. From all the concentrations tested, the MIC differed according to the bacteria specie: for $\mathrm{Pg}$, the MIC was $2500 \mu \mathrm{g} / \mathrm{mL}$, whereas it was $5000 \mu \mathrm{g} / \mathrm{mL}$ for $\mathrm{Fn}$. The increase in $\mathrm{ZnO}$ concentration did not result in higher inhibition zones against $\mathrm{Pg}(p \geq 0.599)$. By contrast, the inhibition zones were greater against $F n$ with increased content of $\mathrm{ZnO}(p<0.001)$.

Data from the agar diffusion test are presented in Table 1. All the membranes containing different concentrations of $\mathrm{ZnO}$ presented antibacterial activity against the targeted bacteria, with clear inhibition zones ranging from 6 to $15 \mathrm{~mm}$ in diameter. The PCL membrane containing $30 \mathrm{wt} . \%$ of $\mathrm{ZnO}$ exhibited higher $(p<0.001)$ inhibition zone than the low-concentrated group and against both bacterial species. The PCL/GEL-based membranes applied against $\mathrm{Pg}$ showed similar $(p \geq 0.702)$ antibacterial activity regardless of the concentration of $\mathrm{ZnO}$; however, when applied against $\mathrm{Fn}$, the most concentrated group displayed higher antibacterial activity than the others $(p<0.001)$.

\subsection{Cytotoxicity test}

As shown in Fig. 8, all membranes presented cytocompatibility (i.e. cell viability higher than 50\%), which was different from the positive control (phenol solution), that was toxic to cells, even at low concentrations. Cell viability 

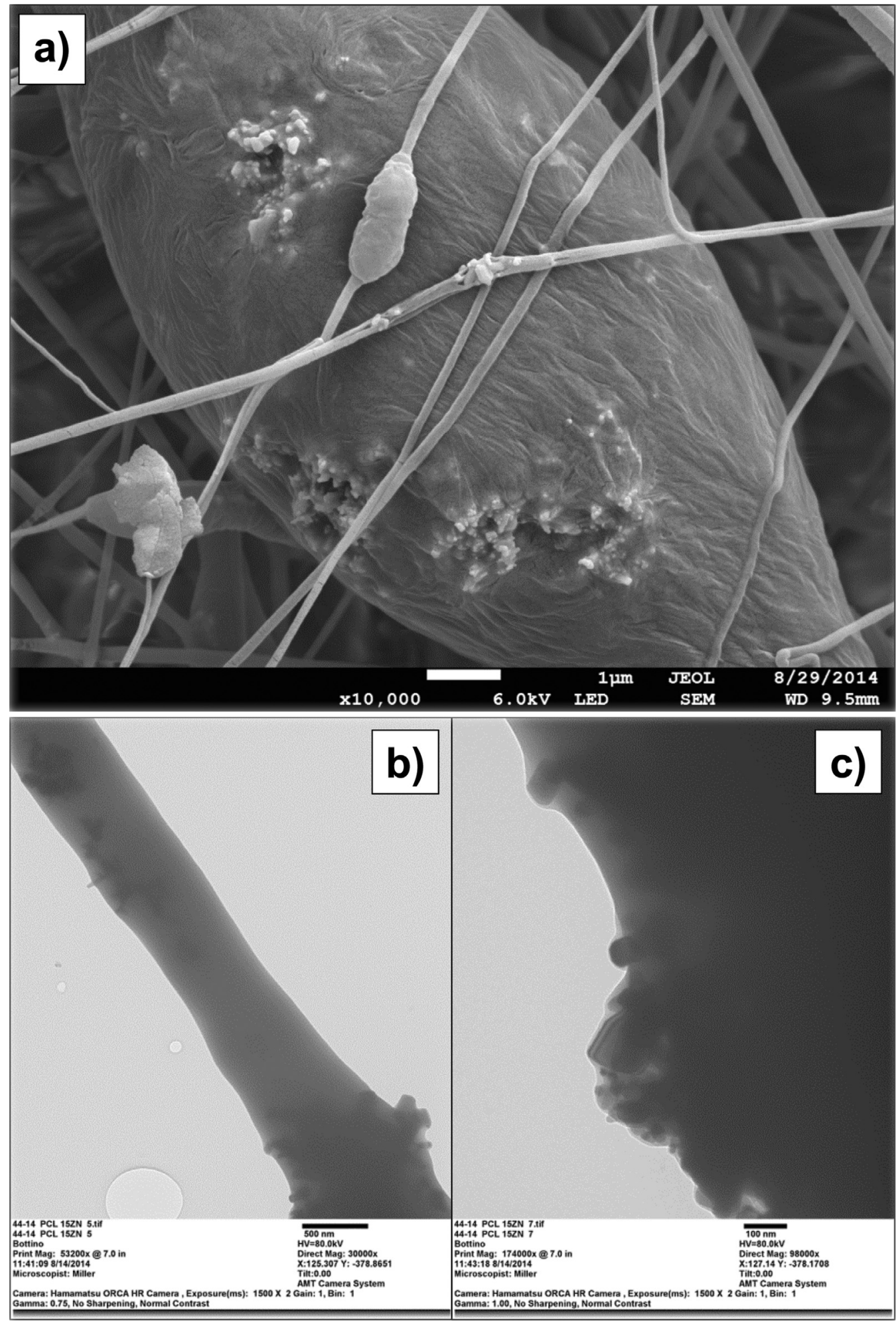

Fig. 2 - (a) Representative SEM micrograph of the PCL nanocomposite membrane containing 30 wt.\% of ZnO showing the accumulation/agglomeration of ZnO nanoparticles on the surface of the fibers. (b and c) TEM images showing the rough surface obtained within the ZnO-incorporated fibers at different magnifications: (b) 30,000x, and (c) $98,000 x$.

remained at an optimal level with $\mathrm{ZnO}$ content up to $15 \mathrm{wt} . \%$; nonetheless, incorporation of a higher amount of nanoparticles resulted in a slight toxic effect on the cells, with the PCL/GEL-based membrane producing the highest cytotoxic potential.

\section{Discussion}

In this study, we investigated extensively both the morphology and microstructure of the electrospun membranes. According 


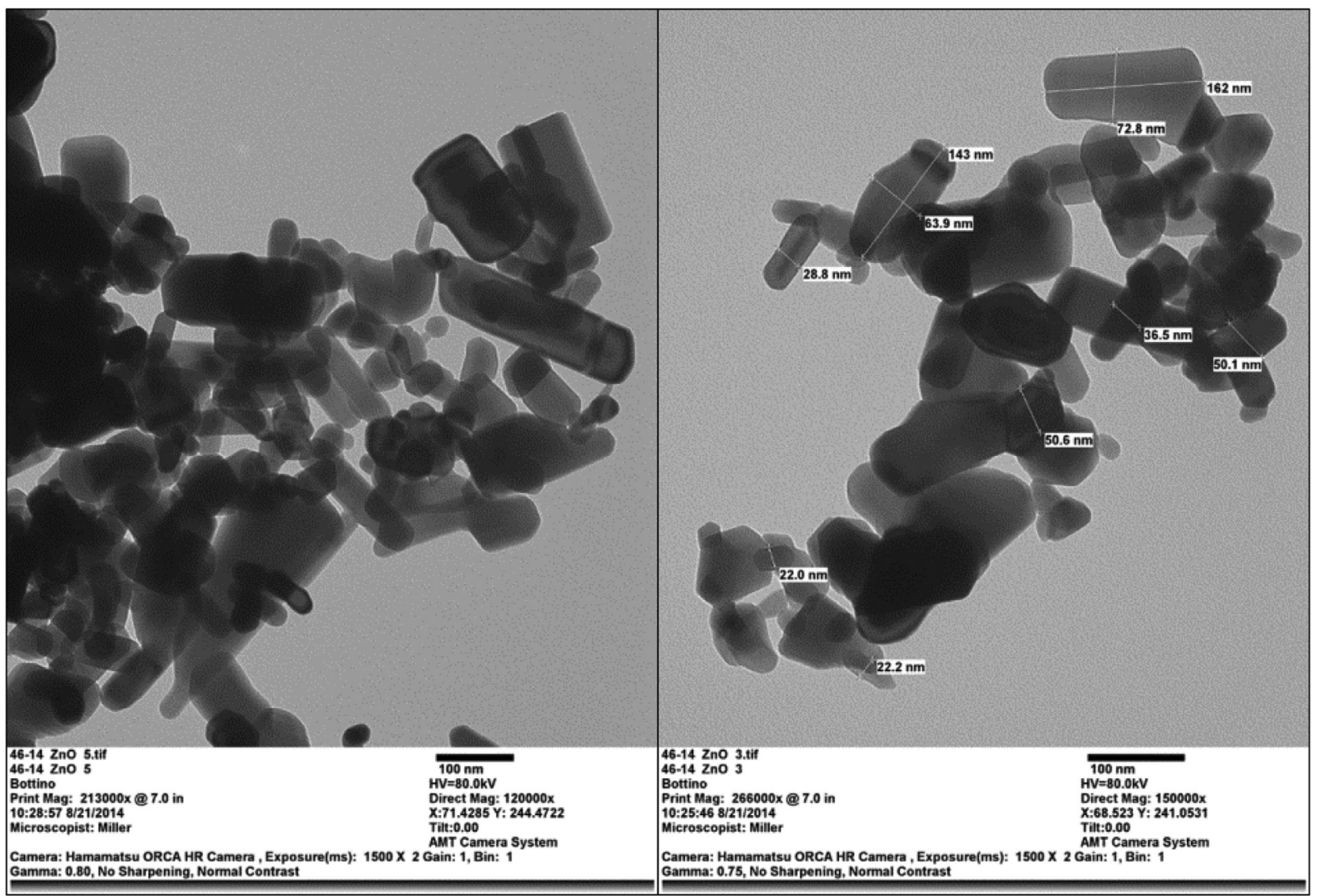

Fig. 3 - TEM images showing the overall morphology and size distribution of the ZnO nanoparticles used. Image on the left and right illustrate, respectively, magnifications of 120,000x and 150,000x.

to the SEM micrographs shown in Fig. 1a, the membranes demonstrated noticeable differences in regard to the morphology of the fibers, which was influenced by the polymer system and the content of the $\mathrm{ZnO}$ that was incorporated. The PCL-based membranes showed a more heterogeneous fiber distribution, whereas the PCL/GEL-based membranes presented fibers with a much lower distribution range, probably due to the increase in viscosity achieved through gelatine addition, leading to a more satisfactory chain entanglement, and thus to the formation of homogeneous fibers [37]. Moreover, even though we did not determine the viscosity of the polymer solution or the polymer blend, one would consider

Table 1 - Antibacterial activity. Mean ( \pm standard deviation) of the inhibition halos (in $\mathrm{mm}$ ) of the zinc oxide (ZnO) nanoparticles suspensions and of the prepared electrospun membranes against Porphyromonas gingivalis (Pg) and Fusobacterium nucleatum (Fn).

\begin{tabular}{|c|c|c|c|c|}
\hline \multirow[t]{2}{*}{ Bacteria } & \multirow[t]{2}{*}{ CHX (control) } & \multicolumn{3}{|c|}{$\mathrm{MIC}$, in $\mu \mathrm{g} / \mathrm{mL}$} \\
\hline & & 2500 & 5000 & 10,000 \\
\hline $\mathrm{Pg}$ & ${ }^{\mathrm{A}} 11.7( \pm 0.6)^{\mathrm{a}}$ & A8.3 $( \pm 1.2)^{b}$ & A9.0 $( \pm 1.0)^{\mathrm{b}}$ & A8.0 $( \pm 0.6)^{b}$ \\
\hline Fn & A $10.3( \pm 0.6)^{\mathrm{a}}$ & ${ }^{\mathrm{B}} 0.0^{\mathrm{C}}$ & ${ }^{B} 5.3( \pm 0.6)^{b}$ & ${ }^{\mathrm{A}} 9.3( \pm 1.2)^{\mathrm{a}}$ \\
\hline \multirow[t]{2}{*}{ ZnO content (wt.\%) } & \multicolumn{2}{|c|}{$\mathrm{Pg}$} & \multicolumn{2}{|c|}{ Fn } \\
\hline & PCL & PCL/GEL & PCL & PCL/GEL \\
\hline 0 & $\mathrm{c}_{0.0^{\mathrm{a}}}$ & $\mathrm{C}_{0.0^{\mathrm{a}}}$ & $\mathrm{D}_{0.0^{\mathrm{a}}}$ & ${ }^{c_{0}} 0.0^{a}$ \\
\hline 5 & ${ }^{\mathrm{B}} 6.3( \pm 0.6)^{\mathrm{b}}$ & в $7.7( \pm 0.6)^{\mathrm{a}}$ & $\mathrm{C}_{6.7}( \pm 1.2)^{\mathrm{b}}$ & ${ }^{\mathrm{B}} 11.3( \pm 0.6)^{\mathrm{a}}$ \\
\hline 15 & $\mathrm{AB} 9.0( \pm 1.0)^{\mathrm{a}}$ & B $8.3( \pm 0.6)^{\mathrm{a}}$ & BC $9.0( \pm 1.7)^{\mathrm{b}}$ & ${ }^{\mathrm{B}} 11.7( \pm 0.6)^{\mathrm{a}}$ \\
\hline 30 & $\mathrm{~A} 11.7( \pm 2.9)^{\mathrm{a}}$ & B $8.3( \pm 0.6)^{b}$ & $\mathrm{~A}_{14.3}( \pm 0.6)^{\mathrm{a}}$ & A $13.7( \pm 0.6)^{\mathrm{a}}$ \\
\hline CHX (control) & ${ }^{\mathrm{AB}} 10.0( \pm 1.0)^{\mathrm{a}}$ & A $11.0( \pm 1.0)^{\mathrm{a}}$ & B $9.7( \pm 0.6)^{\mathrm{b}}$ & ${ }^{\mathrm{AB}} 12.3( \pm 0.6)^{\mathrm{a}}$ \\
\hline
\end{tabular}




\section{a) PCL fibers}

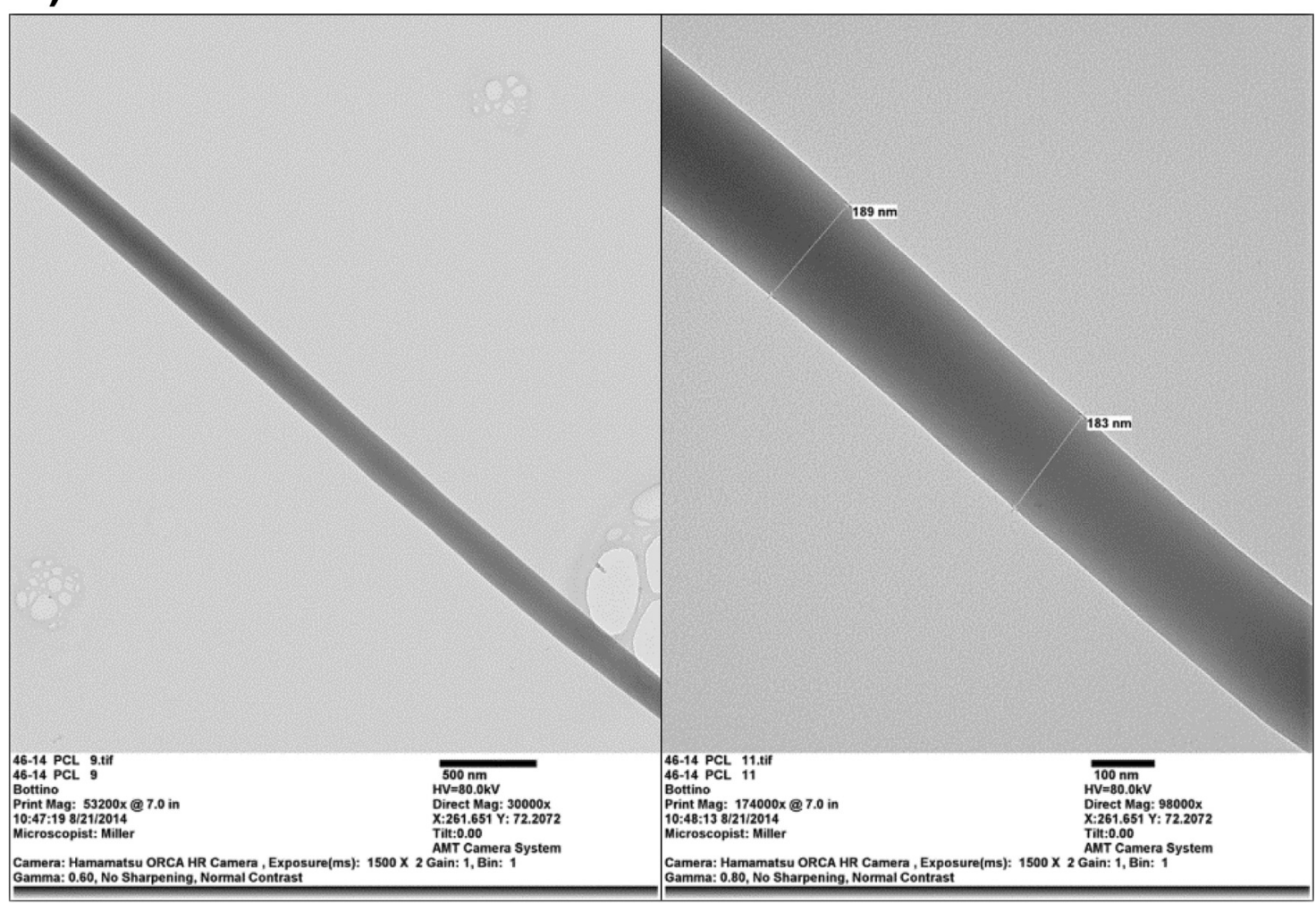

\section{b) ZnO-incorporated PCL fibers}

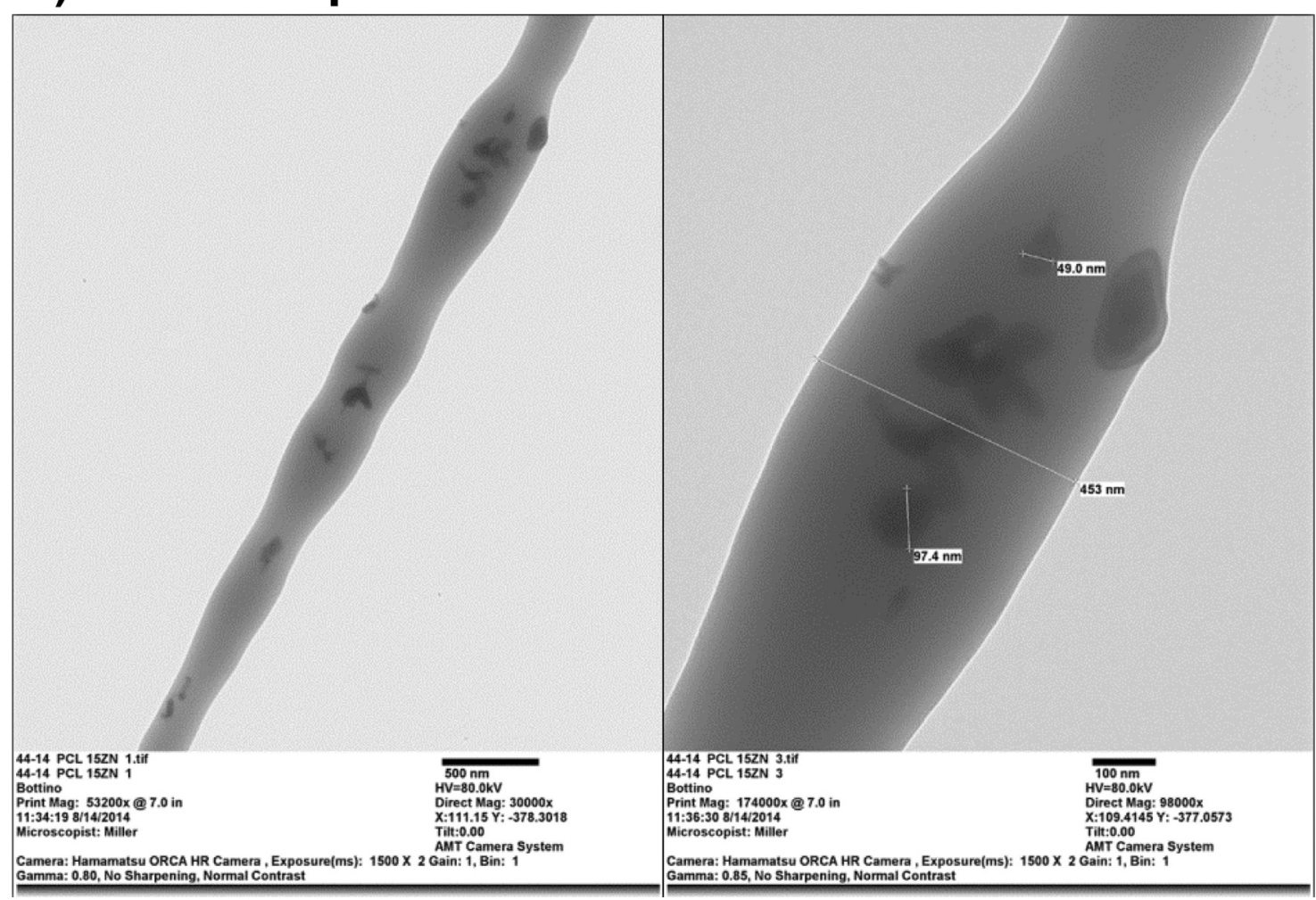

Fig. 4 - TEM images demonstrating, respectively, the absence and the presence of ZnO nanoparticles within the neat PCL fibers (a) and ZnO-incorporated fibers (b). Images on the left and right show, respectively, magnifications of 30,000x and $98,000 x$. 

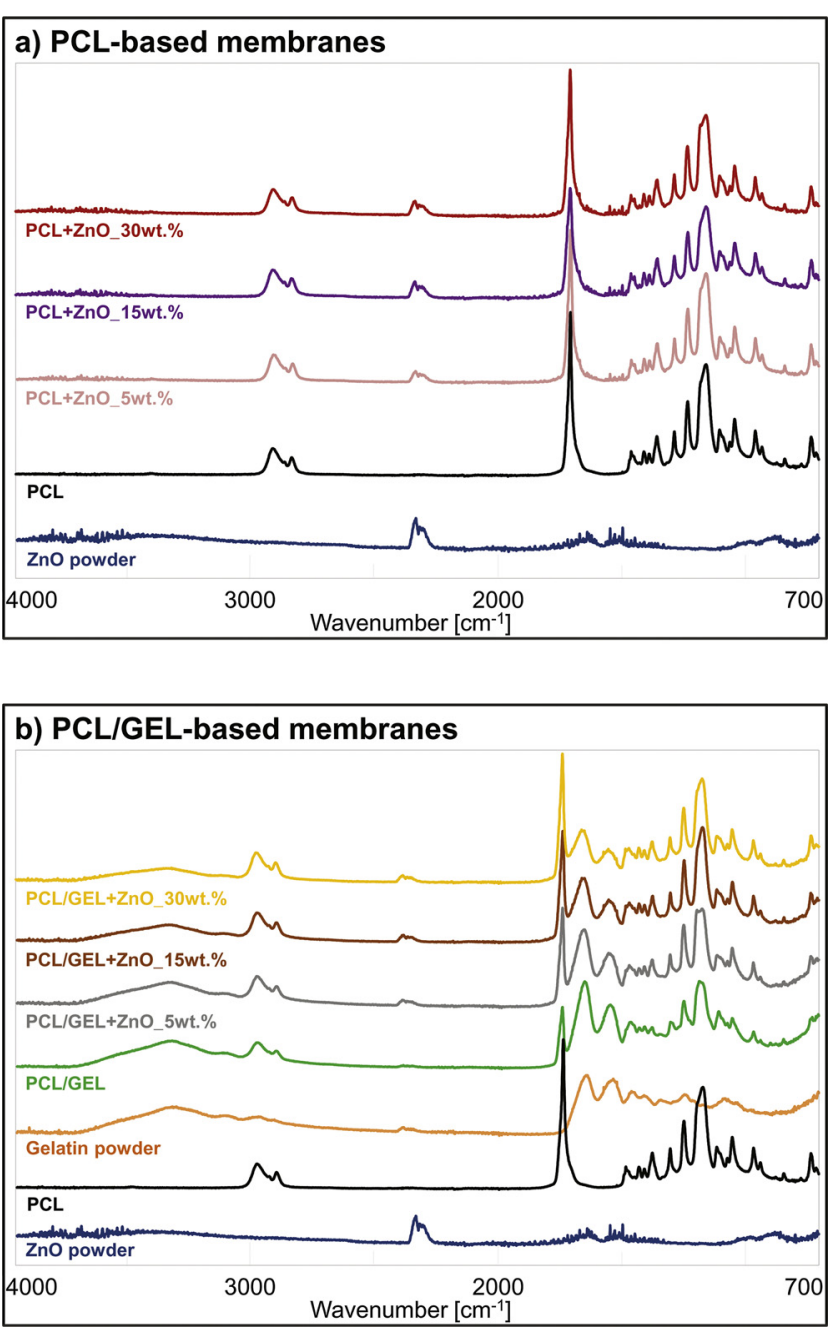

Fig. 5 - ( $a$ and $b$ ) FTIR spectra confirming the incorporation of ZnO and gelatin into the PCL- and PCL/GEL-based membranes.

that the increased viscosity of the gelatine-based solutions might also have contributed to the occurrence of thicker fibers compared to those gelatine-free, corroborating previous findings [29]. Nonetheless, this effect was observed only within the neat fibers and the membrane containing $5 \mathrm{wt}$.\% of $\mathrm{ZnO}$, since the addition of higher amounts of $\mathrm{ZnO}$ nanoparticles (e.g. 15 and 30 wt.\%) progressively reduced fiber diameter. One possible explanation is that both gelatine and $\mathrm{ZnO}$ nanoparticles can increase the electrical conductivity of the polymer solution [38,39], acting synergistically toward the increase in charge density on the surface of the ejected spinning jet, leading to a reduction of self-repulsion tension, and consequently to the increase in elongation forces and the formation of thinner fibers [25,40]. Interestingly, the incorporation of $\mathrm{ZnO}$ nanoparticles into the PCL/GEL solutions produced smooth fibers, with only some areas displaying surface irregularities similar to a bead-like structure. Conversely, the addition of $30 \mathrm{wt} . \% \mathrm{ZnO}$ particles into the PCL-based solution substantially modified the fibers' morphology, which became thicker and rougher compared to the other membranes, probably due to the agglomeration of $\mathrm{ZnO}$ (Fig. 2a) on the surface and inner structure of the fibers [25]. ZnO nanoparticles present high surface energy, thus they tend to agglomerate when mixed at higher concentrations, forming clusters along the fiber length, and consequently resulting in important morphological change. These characteristics may negatively influence cell proliferation [41], thus limiting the use of PCL membranes containing high ZnO nanoparticles' content (in this study - 30 wt.\%) as GTR/GBR membranes. Nonetheless, the presence of gelatine in the PCL solution allowed for the incorporation of a higher $\mathrm{ZnO}$ amount (i.e. $30 \mathrm{wt} . \%$ ) without deleterious changes in the morphology and microstructure of the obtained membranes.

Though the presence of ZnO nanoparticles can be fairly well noticed in some of the SEM micrographs shown in Figs. 1a and 2a, EDS (Fig. 1b), TEM (Fig. 4), and FTIR (Fig. 5a) analyses confirmed the presence of $\mathrm{ZnO}$ trapped within the PCL matrix. Taken together, these results confirmed the chemical characteristics of the membranes synthesized in the study.

ZnO nanoparticles are not soluble in water. More importantly, considering that PCL is also hydrophobic $[29,31]$, one can expect that the ZnO-incorporated PCL membranes would demonstrate poor wettability. Nonetheless, optimal wettability is an important characteristic aimed at GTR/GBR membranes [4], since the membranes are placed in direct contact with moisture (i.e. fluids present in the periodontal surgical site). Furthermore, several studies have demonstrated that hydrophilic scaffolds can display enhanced cell affinity, thus allowing improved cell proliferation and wound healing $[30,42]$. To that end, gelatine, a natural polymer, has been commonly used as an additive to PCL solutions in an attempt to increase scaffold hydrophilicity. Although cells can attach and grow in both pure PCL and PCL/GEL membranes, cell spreading and migration have been improved within gelatine-containing membranes [31]. According to Fig. 6, all PCL-based membranes presented a hydrophobic surface (i.e. contact angle higher than $90^{\circ}$ ), showing poor wettability [43]. By contrast, PCL/GEL membranes revealed excellent wettability/hydrophilicity. An interesting finding of the present study was that the PCL/GEL membranes containing 5 and $15 \mathrm{wt}$.\% of $\mathrm{ZnO}$ nanoparticles were more hydrophilic than the other gelatine-based membranes $(p<0.001)$. In fact, $10 \mathrm{~s}$ after the water drop (i.e. time set to allow the drop to accommodate and interact with the surface [44]), the membranes containing low (5 wt.\%) and medium (15 wt.\%) ZnO contents could not maintain a convex shape of the water drops, thus precluding the contact angle measurement. This, perhaps, demonstrates that the latter membranes were very hydrophilic, and therefore, they can be considered promising for GTR/GBR applications. One can also note that the same effect was not seen for the PCL/GEL membrane containing $\mathrm{ZnO}$ nanoparticles at $30 \mathrm{wt}$.\%, which may possibly be explained by the occurrence of van der Waals physical interactions between the nanoparticles and PCL polymer chains, as previously suggested [25]. These physical interactions, which may have become more intense at higher $\mathrm{ZnO}$ contents (e.g. $30 \mathrm{wt} . \%)$, could have slightly reduced the surface energy of the membrane, thus resulting in lower wettability [43], although still hydrophilic (i.e. contact angle lower than $90^{\circ}$ ) and comparable to the ZnO-free PCL/GEL membrane.

As previously highlighted, despite adequate morphology, microstructure, and wettability, GTR/GBR membranes 


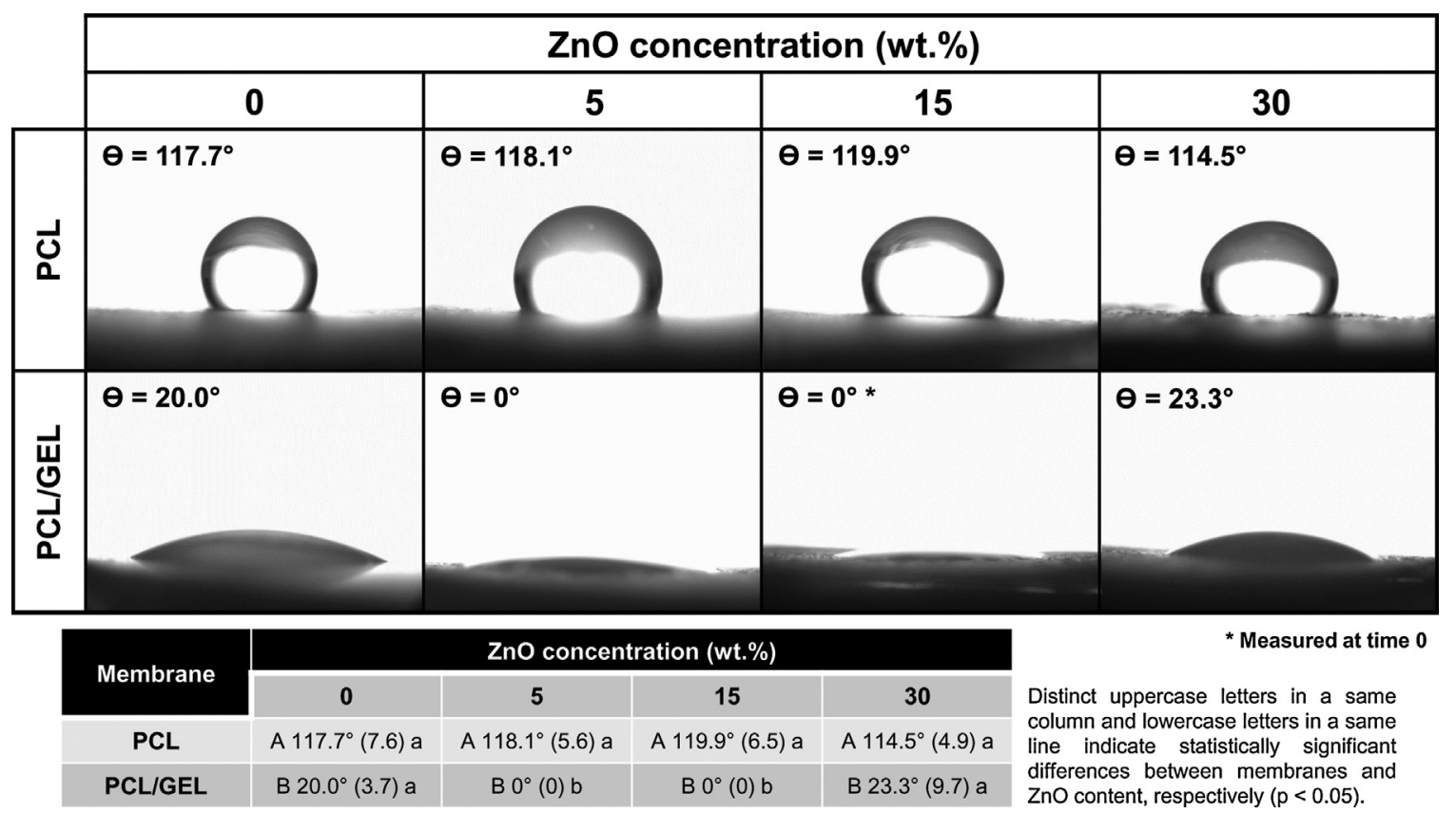

Fig. 6 - Images of the contact angle formed between water and the PCL- or PCL/GEL-based membranes containing different concentrations of $\mathrm{ZnO}$ nanoparticles.

should also present satisfactory mechanical properties to avoid membrane collapse into the periodontal defect as a result of compression forces of the soft tissues and mastication [4,7]. Furthermore, GTR/GBR membranes need to display appropriate stiffness to withstand cell attachment and proliferation; otherwise, the membranes may not be clinically useful $[4,7,9,12]$. A recent study demonstrated that cell viability and proliferation of 3T3 fibroblasts cultured on stiffer membranes were higher than on softer ones [45]. Findings from another investigation showed that the increase in elastic modulus obtained with the incorporation of alginate in a PCL-based membrane resulted in improved cell viability, as well as other important cell activity parameters (e.g. cell proliferation, alkaline phosphatase activity, and mineralization ability) [46]. Considering these foregoing statements, the mechanical performance (e.g. tensile strength, Young's modulus, and elongation at break) of the synthesized membranes was assessed, under dry and wet conditions by uni-axial tensile testing. The results obtained in this study (Fig. 7) corroborate the findings of some previous studies, which demonstrated that blending gelatine with synthetic polymers, such as PCL, can increase the crystallinity [29] and mechanical strength of fibers [28-30,42], although their storage in wet media may produce an inverse effect, since gelatine usually does not cross-link to the main polymer chain, leading to fast hydrolytic degradation of the system and a reduction of properties [29]. Worth mentioning, the use of crosslinking agents (i.e. glutaraldehyde, genipin, etc.) can potentially enhance the mechanical properties of these gelatine-containing membranes, since crosslinking reactions can be produced, leading to improved mechanical properties and degradation resistance $[47,48]$. This would be an interesting focus for future studies. With regard to $\mathrm{ZnO}$ incorporation, an overall analysis of the tensile strength, Young's modulus, and elongation at break of the PCL and PCL/GELbased membranes, revealed a decrease, corroborating with a previous study [25], perhaps with two exceptions: (1) the rigidity of the PCL membrane was maintained with the incorporation of $30 \mathrm{wt} . \%$ nanoparticles and (2) flexibility was significantly increased. This can probably result from microstructure of the aforementioned membrane, which showed thicker fibers (Figs. $1 \mathrm{a}$ and 2a) that withstood higher loading during testing and improved flexibility. Nonetheless, and as stated before, this membrane would not be ideal for GTR/GBR application, since the microstructure/morphology of fibers lacked in satisfactory characteristics that resemble the ECM of native bone [4].

Another important goal of this study was to demonstrate that $\mathrm{ZnO}$-incorporated membranes show antimicrobial activity when compared to their $\mathrm{ZnO}$-free counterparts against common periodontopathogens. First, the minimum inhibitory concentration (MIC) of ZnO nanoparticles was determined using suspensions of $\mathrm{ZnO}$ in PBS. According to Table 1, against $\mathrm{Pg}$, the MIC was $2500 \mu \mathrm{g} / \mathrm{mL}$, whereas against Fn it was $5000 \mu \mathrm{g} / \mathrm{mL}$. These results are quite different from a previous study, which demonstrated that the MIC of ZnO was $250 \mu \mathrm{g} / \mathrm{mL}$ against both $\mathrm{Pg}$ and $\mathrm{Fn}$ [49]. That concentration, perhaps, was not effective in our study, and this may be due to the characteristics of the $\mathrm{ZnO}$ nanoparticles used. According to recent studies [50,51], differences in nanoparticle size may play a significant role in the antibacterial potential, with smaller particles demonstrating higher surface area, and therefore, enhanced inhibitory effects. The study by Vargas-Reus et al. [49] tested nanoparticles ranging from 10 to $50 \mathrm{~nm}$, whereas the nanoparticles used in the present study had an average size of $65 \mathrm{~nm}$ (Fig. 4). Consequently, the surface area of the $\mathrm{ZnO}$ particles used here was reduced, requiring an increased MIC (Table 1). Interestingly, increased concentrations of $\mathrm{ZnO}$ 


\section{DRY}

(a)

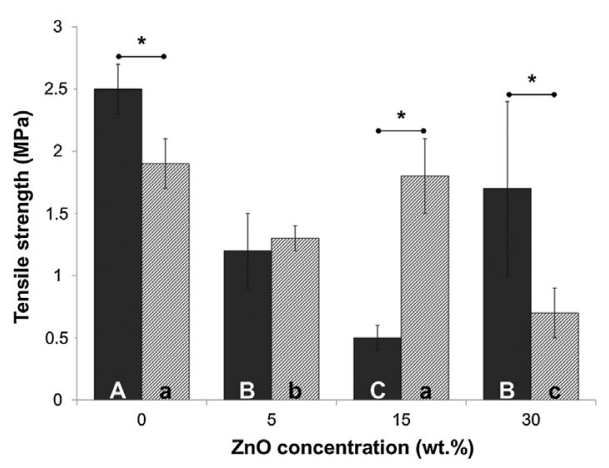

(b)

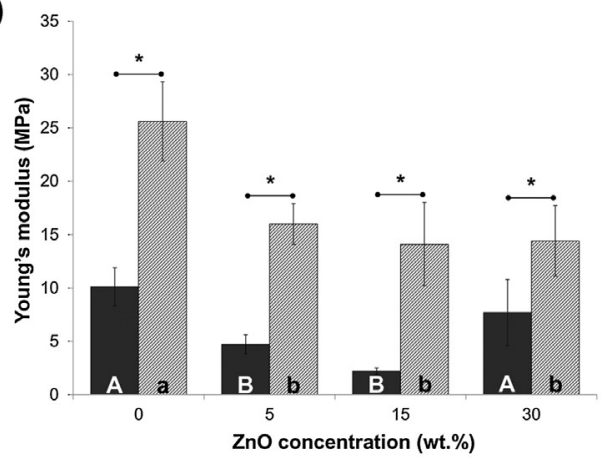

(c)

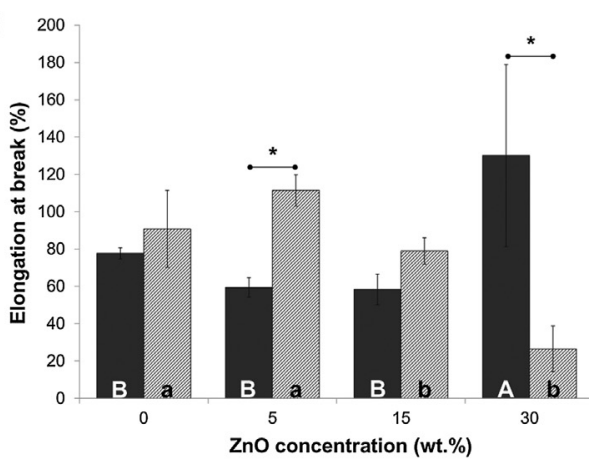

Tensile strength

PCL-based membranes

PCL/GEL-based membranes

\section{Young's modulus}

PCL-based membranes

PCL/GEL-based membranes

\section{Elongation at break}

PCL-based membranes

PCL/GEL-based membranes
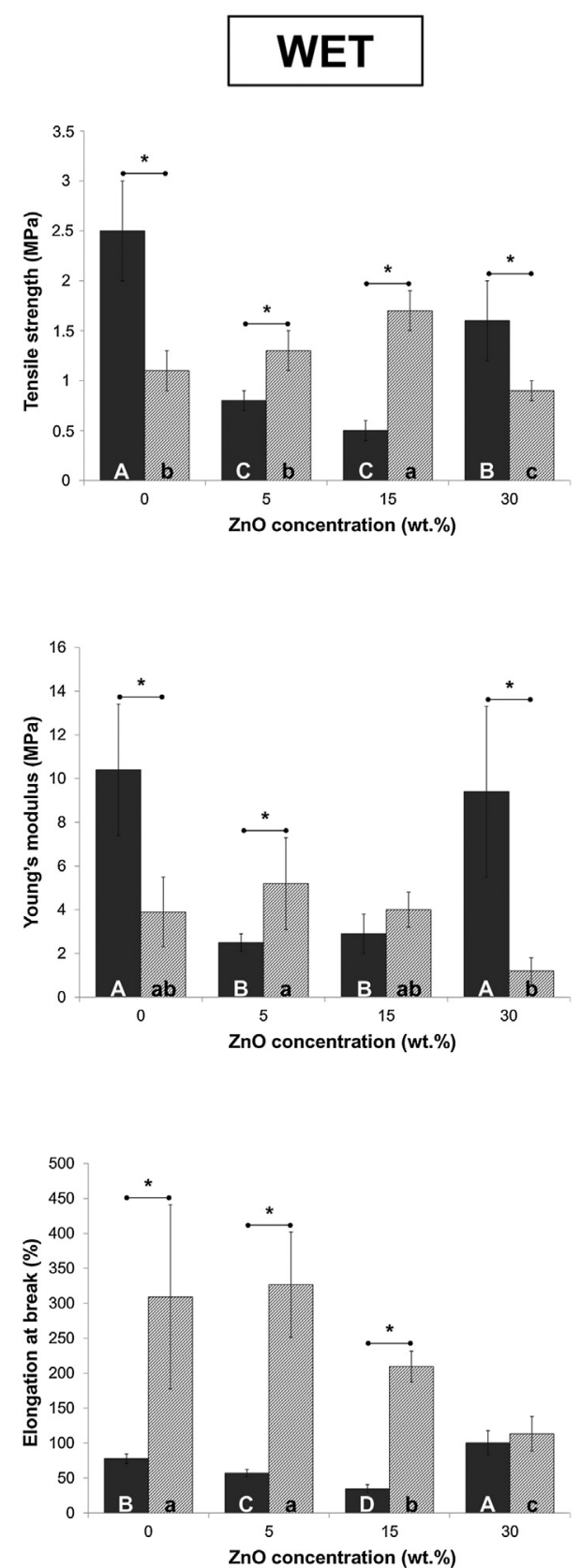

Fig. 7 - Mechanical characteristics of the PCL- and PCL/GEL-based membranes synthesized in the study, under dry (graphs on the left) and wet (graphs on the right) conditions: (a) tensile strength, in MPa; (b) Young's modulus, in MPa; and (c) ELONGATION at break, in \%. Horizontal lines with asterisks over the SD bars represent statistically significant difference between dry and wet conditions.

did not result in higher inhibition zones against $\mathrm{Pg}$, whereas the antibacterial activity of $\mathrm{ZnO}$ against $\mathrm{Fn}$ was greater at $10,000 \mu \mathrm{g} / \mathrm{mL}$ when compared to the $5000 \mu \mathrm{g} / \mathrm{mL}$ concentration. According to these results, the minimum $\mathrm{ZnO}$ dose to be tested in the present investigation for preparing the PCL- and PCL/GEL-based solutions was 5 wt.\%, which corresponded to the $5000 \mu \mathrm{g} / \mathrm{mL}$ concentration (i.e. the $\mathrm{ZnO}$ concentration that was effective against both bacteria species).

Even though the mechanism of action of $\mathrm{ZnO}$ is still vaguely understood, it has been reported that the nanoparticles can produce reactive oxygen species (ROS), such as hydroxyl radicals, super oxides, and hydrogen peroxide, which may penetrate the cell wall and affect bacteria integrity [52-54]. In the present study, the antibacterial activity displayed by the $\mathrm{ZnO}$-incorporated membranes seemed to be dose-dependent, since the $30 \mathrm{wt}$ \% concentration resulted in higher inhibition zones when compared to the less concentrated groups (Table 1). Indeed, it is expected that the higher the amount of nanoparticles incorporated, the greater the availability of active compound to diffuse into the agar medium and effectively inhibit bacterial growth [26]. Notwithstanding, the only exception was seen within the PCL/GEL-based membranes 

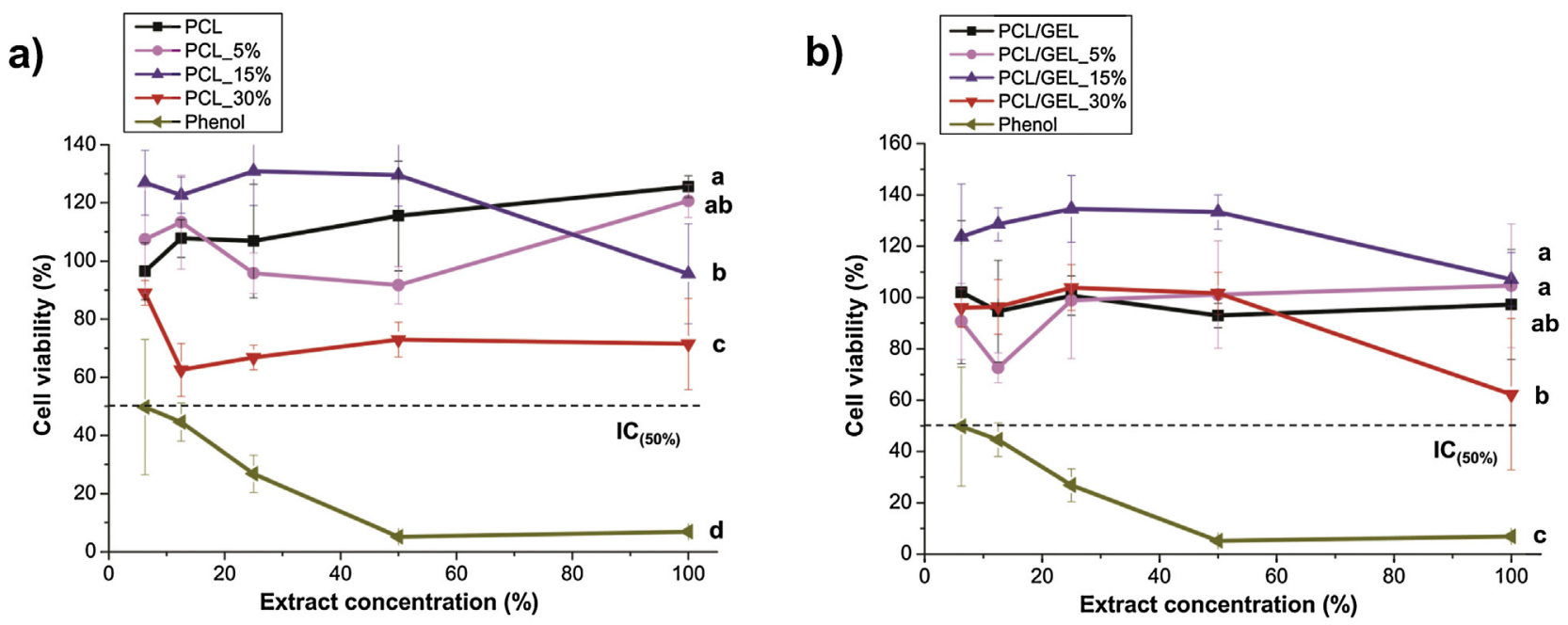

c)

\begin{tabular}{|c|c|c|c|c|}
\hline \multirow{2}{*}{ Membranes } & \multicolumn{4}{|c|}{ ZnO content (wt.\%) } \\
\cline { 2 - 5 } & $\mathbf{0}$ & $\mathbf{5}$ & $\mathbf{1 5}$ & $\mathbf{3 0}$ \\
\hline PCL & $\mathrm{A} 125.5( \pm 3.8) \mathrm{a}$ & $\mathrm{A} 120.6( \pm 5.7) \mathrm{a}$ & $\mathrm{A} 95.6( \pm 17.2)$ ab & $\mathrm{A} 71.5( \pm 15.7) \mathrm{b}$ \\
\hline PCL/GEL & $\mathrm{B} 97.3( \pm 21.4) \mathrm{ab}$ & $\mathrm{A} 104.7( \pm 24.1) \mathrm{a}$ & $\mathrm{A} 107.1( \pm 10.4) \mathrm{a}$ & $\mathrm{A} 62.3( \pm 29.5) \mathrm{b}$ \\
\hline
\end{tabular}

Distinct uppercase letters before means and lowercase letters after standard deviations $( \pm S D)$ indicate, respectively, statistically significant differences between the membranes (in columns) and among zinc oxide ( $\mathrm{ZnO})$ content (in rows) $(\mathrm{p}<0.05)$.

Fig. 8 - Cytotoxicity assays results of the PCL- (a) and PCL/GEL-based (b) membranes and cell viability means (in \%) and standard deviations ( \pm SD) after exposure to the full-concentrated (i.e. 100\% extract concentration, non-diluted) extracts (c).

applied against $\mathrm{Pg}$, which showed similar antibacterial activity regardless of the concentration of ZnO. These findings may suggest that gelatine-based materials can interact differently with the bacteria surface, depending on the specie evaluated. According to Bhadra et al. [55], amino-based molecules, such as gelatine, can interact with the outermost cell membrane of some bacteria by means of amino groups (-NH2), enhancing permeability of the latter, and consequently, resulting in its destruction/death. This last mechanism might explain the greater antibacterial activity of the PCL/GEL-based membranes against $F n$, which exhibited inhibition zones ranging from 11 to $14 \mathrm{~mm}$, and in comparison with $\mathrm{Pg}$ (Table 1), whose inhibition zones ranged from 8 to $9 \mathrm{~mm}$ in diameter, only. This is probably due to structural differences [49] between the bacteria investigated and possible differences in their intracellular antioxidant content [56]. In light of this, the antibacterial potential of ZnO-incorporated membranes should be also investigated against different bacteria from those tested here, such as facultative anaerobic species, including but not limited to A. actinomycetemcomitans. Notwithstanding, and after all, the $\mathrm{ZnO}$-incorporated membranes prepared in this study are promising candidates for GTR/GBR applications, showing antibacterial properties that would potentially prevent infection and/or recolonization of bacteria at the periodontal site.

Considering that cells need a proper substrate to attach and proliferate in, apart from important membrane/scaffold characteristics, such as fiber shape, fiber diameter/distribution, pore structure, wettability to facilitate protein adsorption, and cell attachment, GTR/GBR ZnO-loaded membranes should invariably be biocompatible. We investigated cell compatibility using human dental pulp stem cells, knowing their significant osteogenic differentiation potential [43,57], key in periodontal bone regeneration. As shown in Fig. 8, all membranes presented cytocompatibility (i.e. cell viability higher than $50 \%$ ), which was different from the positive control (phenol solution), that was toxic to cells, even at low concentrations. It is important to note that cell viability remained at an optimal level, even with $\mathrm{ZnO}$ content up to $15 \mathrm{wt}$ \%, thus confirming the biocompatible nature of the $\mathrm{ZnO}$-incorporated membranes. Nonetheless, incorporation of a higher amount of nanoparticles resulted in a slight toxic effect on the cells, with the PCL/GEL-based membrane producing the highest cytotoxic potential. These findings corroborate previous studies, which reported that, at low concentration ( $<5 \mathrm{wt} . \%) \mathrm{ZnO}$ is not harmful to cells $[23,25,58]$. Notwithstanding, the amount incorporated in the present study was significantly higher when compared to these previous studies, but it still did not show strong cytotoxicity, even at the $30 \mathrm{wt}$.\% concentration. This may suggest that, perhaps the nanoparticles were homogeneously distributed within the fibers, which may, in turn, contribute to a proper and safe release of $\mathrm{ZnO}$ to the periodontal site.

One should note that the scope of the cell-related work presented in this study was limited. Future studies should investigate the effects of $\mathrm{ZnO}$ from a molecular standpoint to better understand its role on DPSC cell functions and its differentiation before in vivo testing using GTR/GBR periodontal defect models. 


\section{Conclusion}

The fabrication of a novel, biocompatible periodontal fibrous membrane with antibacterial properties provided by zinc oxide nanoparticles was reported. This electrospun membrane holds promise in terms of microstructure/morphology that resembles the extracellular matrix of native tissues, wettability characteristics, mechanical integrity, antibacterial activity against common periodontopathogens, and cytocompatibility to human dental pulp stem cells. It was demonstrated that the incorporation of a low amount of zinc oxide nanoparticles can improve the bioactivity of the membranes that may be potentially applied for GTR/GBR applications, therefore leading to an enhanced and predictable periodontal regeneration.

\section{Conflict of interest}

No conflicts of interest were declared.

\section{Acknowledgements}

M.C.B. acknowledges start-up funds from the Indiana University School of Dentistry, the NIH/NIDCR (Grant\#DE023552), and an International Development Funds (IDF) Grant from Indiana University Purdue University (IUPUI/OVCR).

\section{REFERENCES}

[1] Albandar JM, Brunelle JA, Kingman A. Destructive periodontal disease in adults 30 years of age and older in the United States, 1988-1994. J Periodontol 1999;70:13-29.

[2] Haffajee AD, Socransky SS. Microbial etiological agents of destructive periodontal diseases. Periodontol 2000 1994;5:78-111.

[3] Kassebaum NJ, Bernabe E, Dahiya M, Bhandari B, Murray CJ, Marcenes W. Global burden of severe periodontitis in 1990-2010: a systematic review and meta-regression. J Dent Res 2014;93:1045-53.

[4] Bottino MC, Thomas V, Schmidt G, Vohra YK, Chu TM, Kowolik MJ, et al. Recent advances in the development of GTR/GBR membranes for periodontal regeneration-a materials perspective. Dent Mater 2012;28:703-21.

[5] Keestra JA, Grosjean I, Coucke W, Quirynen M, Teughels W. Non-surgical periodontal therapy with systemic antibiotics in patients with untreated chronic periodontitis: a systematic review and meta-analysis. J Periodontal Res 2015;50:294-314.

[6] Bottino MC, Arthur RA, Waeiss RA, Kamocki K, Gregson KS, Gregory RL. Biodegradable nanofibrous drug delivery systems: effects of metronidazole and ciprofloxacin on periodontopathogens and commensal oral bacteria. Clin Oral Investig 2014;18:2151-8.

[7] Bottino MC, Thomas V, Janowski GM. A novel spatially designed and functionally graded electrospun membrane for periodontal regeneration. Acta Biomater 2011;7: 216-24.

[8] Cochran DL, Cobb CM, Bashutski JD, Chun YH, Lin Z, Mandelaris G, et al. Emerging regenerative approaches for periodontal reconstruction: a consensus report. J Periodontol 2014;15(October):1-5 [epub ahead of print].
[9] Fujihara K, Kotaki M, Ramakrishna S. Guided bone regeneration membrane made of polycaprolactone/calcium carbonate composite nano-fibers. Biomaterials 2005;26:4139-47.

[10] Li WJ, Cooper Jr JA, Mauck RL, Tuan RS. Fabrication and characterization of six electrospun poly(alpha-hydroxy ester)-based fibrous scaffolds for tissue engineering applications. Acta Biomater 2006;2:377-85.

[11] Schofer MD, Roessler PP, Schaefer J, Theisen C, Schlimme S, Heverhagen JT, et al. Electrospun PLLA nanofiber scaffolds and their use in combination with BMP-2 for reconstruction of bone defects. PLoS ONE 2011;6:e25462.

[12] Yang F, Both SK, Yang X, Walboomers XF, Jansen JA. Development of an electrospun nano-apatite/PCL composite membrane for GTR/GBR application. Acta Biomater 2009;5:3295-304.

[13] Johnson LR, Stoller NH. Rationale for the use of Atridox therapy for managing periodontal patients. Compend Contin Educ Dent 1999;20:19-25.

[14] Salvi GE, Mombelli A, Mayfield L, Rutar A, Suvan J, Garrett S, et al. Local antimicrobial therapy after initial periodontal treatment. J Clin Periodontol 2002;29:540-50.

[15] Chen DW, Lee FY, Liao JY, Liu SJ, Hsiao CY, Chen JK. Preclinical experiments on the release behavior of biodegradable nanofibrous multipharmaceutical membranes in a model of four-wall intrabony defect. Antimicrob Agents Chemother 2013;57:9-14.

[16] Goudouri OM, Kontonasaki E, Lohbauer U, Boccaccini AR. Antibacterial properties of metal and metalloid ions in chronic periodontitis and peri-implantitis therapy. Acta Biomater 2014;10:3795-810.

[17] Hans M, Erbe A, Mathews S, Chen Y, Solioz M, Mucklich F. Role of copper oxides in contact killing of bacteria. Langmuir 2013;29:16160-6.

[18] Hwang SH, Song J, Jung Y, Kweon OY, Song H, Jang J. Electrospun $\mathrm{ZnO} / \mathrm{TiO}_{2}$ composite nanofibers as a bactericidal agent. Chem Commun 2011;47:9164-6.

[19] Sawai J, Yoshikawa T. Quantitative evaluation of antifungal activity of metallic oxide powders $(\mathrm{MgO}, \mathrm{CaO}$ and $\mathrm{ZnO})$ by an indirect conductimetric assay. J Appl Microbiol 2004;96:803-9.

[20] FDA Part 182 - Substances generally recognized as safe. Food and drug administration. Washington, DC, USA, 2014. Available at: http://www.ecfr.gov/cgi-bin/text-dx?c=ecfr\& sid=786bafc6f6343634fbf79fcdca7061e1\&rgn=div5\&view= text\&n ode=21:3.0.1.1.13\&idno=21 - se21.3.182_18991 [accessed on 26.10.14].

[21] Anitha S, Brabu B, John Thiruvadigal D, Gopalakrishnan C, Natarajan TS. Optical, bactericidal and water repellent properties of electrospun nano-composite membranes of cellulose acetate and ZnO. Carbohydr Polym 2013;97:856-63.

[22] Kasraei S, Sami L, Hendi S, Alikhani MY, Rezaei-Soufi L, Khamverdi Z. Antibacterial properties of composite resins incorporating silver and zinc oxide nanoparticles on Streptococcus mutans and Lactobacillus. Restor Dent Endod 2014;39:109-14

[23] Shalumon KT, Anulekha KH, Nair SV, Nair SV, Chennazhi KP, Jayakumar R. Sodium alginate/poly(vinyl alcohol)/nano ZnO composite nanofibers for antibacterial wound dressings. Int J Biol Macromol 2011;49:247-54

[24] Amna T, Hassan MS, Sheikh FA, Lee HK, Seo KS, Yoon D, et al. Zinc oxide-doped poly(urethane) spider web nanofibrous scaffold via one-step electrospinning: a novel matrix for tissue engineering. Appl Microbiol Biotechnol 2013;97:1725-34.

[25] Augustine R, Dominic EA, Reju I, Kaimal B, Kalarikkal N, Thomas S. Electrospun polycrapolactone membranes incorporated with $\mathrm{ZnO}$ nanoparticles as skin substitutes 
with enhanced fibroblast proliferation and wound healing. RSC Adv 2014;4:24777-85.

[26] Augustine R, Malik HN, Singhal DK, Mukherjee A, Malakar D, Kalarikkal N, et al. Electrospun polycaprolactone/ZnO nanocomposite membranes as biomaterials with antibacterial and cell adhesion properties. J Polym Res 2014;21:347

[27] Dash TK, Konkimalla VB. Polymeric modification and its implication in drug delivery: poly-epsilon-caprolactone (PCL) as a model polymer. Mol Pharm 2012;9:2365-79.

[28] Jin G, Prabhakaran MP, Kai D, Annamalai SK, Arunachalam $\mathrm{KD}$, Ramakrishna S. Tissue engineered plant extracts as nanofibrous wound dressing. Biomaterials 2013;34:724-34.

[29] Nelson MT, Johnson J, Lannutti J. Media-based effects on the hydrolytic degradation and crystallization of electrospun synthetic-biologic blends. J Mater Sci Mater Med 2014;25:297-309.

[30] Zheng R, Duan H, Xue J, Liu Y, Feng B, Zhao S, et al. The influence of Gelatin/PCL ratio and 3-D construct shape of electrospun membranes on cartilage regeneration. Biomaterials 2014;35:152-64.

[31] Zhang Y, Ouyang H, Lim CT, Ramakrishna S, Huang ZM. Electrospinning of gelatin fibers and gelatin/PCL composite fibrous scaffolds. J Biomed Mater Res B Appl Biomater 2005;72:156-65.

[32] Bottino MC, Yassen GH, Platt JA, Labban N, Windsor LJ, Spolnik KJ, et al. A novel three-dimensional scaffold for regenerative endodontics: materials and biological characterizations. J Tissue Eng Regen Med 2013;(March), http://dx.doi.org/10.1002/term.1712 [epub ahead of print].

[33] Palasuk J, Kamocki K, Hippenmeyer L, Platt JA, Spolnik KJ, Gregory RL, et al. Bimix antimicrobial scaffolds for regenerative endodontics. J Endod 2014;40:1879-84.

[34] Bottino MC, Kamocki K, Yassen GH, Platt JA, Vail MM, Ehrlich $Y$, et al. Bioactive nanofibrous scaffolds for regenerative endodontics. J Dent Res 2013;92:963-9.

[35] ISO 10993-5. Biological evaluation of medical devices. Part 5: tests for cytotoxicity: in vitro methods; 1993.

[36] Bottino MC, Coelho PG, Henriques VA, Higa OZ, Bressiani AH, Bressiani JC. Processing, characterization, and in vitro/in vivo evaluations of powder metallurgy processed Ti-13Nb-13Zr alloys. J Biomed Mater Res A 2009;88:689-96.

[37] Dargaville BL, Vaquette C, Rasoul F, Cooper-White JJ, Campbell JH, Whittaker AK. Electrospinning and crosslinking of low-molecular-weight poly(trimethylene carbonate-co-(L)-lactide) as an elastomeric scaffold for vascular engineering. Acta Biomater 2013;9:6885-97.

[38] Janotti A, Van de Walle CG. Fundamentals of zinc oxide as a semiconductor. Rep Prog Phys 2009;72:126501.

[39] Oraby MA, Waley AI, El-Dewany AI, Saad EA, Abd El-Hady BM. Electrospun gelatin nanofibers: effect of gelatin concentration on morphology and fiber diameters. J Appl Sci Res 2013;9:534-40

[40] Zong X, Kim K, Fang D, Ran S, Hsiao BS, Chu B. Structure and process relationship of electrospun bioabsorbable nanofiber membranes. Polymer 2002;43:4403-12.

[41] Christopherson GT, Song H, Mao HQ. The influence of fiber diameter of electrospun substrates on neural stem cell differentiation and proliferation. Biomaterials 2009;30:556-64.

[42] Lee J, Tae G, Kim YH, Park IS, Kim SH, Kim SH. The effect of gelatin incorporation into electrospun poly(L-lactide-co-epsilon-caprolactone) fibers on mechanical properties and cytocompatibility. Biomaterials 2008;29:1872-9.

[43] Zhang J, Kwok DY. Lattice boltzmann study on the contact angle and contact line dynamics of liquid-vapor interfaces. Langmuir 2004;20:8137-41.

[44] Fu W, Liu Z, Feng B, Hu R, He X, Wang H, et al. Electrospun gelatin/PCL and collagen/PLCL scaffolds for vascular tissue engineering. Int J Nanomed 2014;9:2335-44.

[45] Mi HY, Jing X, Salick MR, Cordie TM, Peng XF, Turng LS. Properties and fibroblast cellular response of soft and hard thermoplastic polyurethane electrospun nanofibrous scaffolds. J Biomed Mater Res B Appl Biomater 2014;(August), http://dx.doi.org/10.1002/jbm.b.33271 [epub ahead of print].

[46] Kim MS, Kim G. Three-dimensional electrospun polycaprolactone (PCL)/alginate hybrid composite scaffolds. Carbohyd Polym 2014;114:213-21.

[47] Bottino MC, Thomas V, Jose MV, Dean DR, Janowski GM. Acellular dermal matrix graft: synergistic effect of rehydration and natural crosslinking on mechanical properties. J Biomed Mater Res B Appl Biomater 2010;95:276-82.

[48] Huang GP, Shanmugasundaram S, Masih P, Pandya D, Amara $\mathrm{S}$, Collins $\mathrm{G}$, et al. An investigation of common crosslinking agents on the stability of electrospun collagen scaffolds. J Biomed Mater Res A 2015;103:762-71.

[49] Vargas-Reus MA, Memarzadeh K, Huang J, Ren GG, Allaker RP. Antimicrobial activity of nanoparticulate metal oxides against peri-implantitis pathogens. Int J Antimicrob Agents 2012;40:135-9.

[50] Azam A, Ahmed AS, Oves M, Khan MS, Memic A. Size-dependent antimicrobial properties of $\mathrm{CuO}$ nanoparticles against Gram-positive and -negative bacterial strains. Int J Nanomed 2012;7:3527-35.

[51] Khurana C, Vala AK, Andhariya N, Pandey OP, Chudasama B. Antibacterial activity of silver: the role of hydrodynamic particle size at nanoscale. J Biomed Mater Res A 2014;102:3361-8.

[52] Akbar A, Anal AK. Zinc oxide nanoparticles loaded active packaging, a challenge study against Salmonella typhimurium and Staphylococcus aureus in ready-to-eat poultry meat. Food Control 2014;38:88-95.

[53] Espitia PJP, Soares NFF, Coimbra JSR, Andrade NJ, Cruz RS, Medeiros EAA. Zinc oxide nanoparticles: synthesis, antimicrobial activity and food packaging applications. Food Bioprocess Technol 2012;5:1447-64.

[54] Xie Y, He Y, Irwin PL, Jin T, Shi X. Antibacterial activity and mechanism of action of zinc oxide nanoparticles against Campylobacter jejuni. Appl Environ Microbiol 2011;77: 2325-31.

[55] Bhadra P, Mitra MK, Das GC, Dey R, Mukherjee S. Interaction of chitosan capped $\mathrm{ZnO}$ nanorods with Escherichia coli. Mat Sci Eng 2011;31:929-37.

[56] Applerot G, Lipovsky A, Dror R, Perkas N, Nitzan Y, Lubart R, et al. Enhanced antibacterial activity of nano-crystalline ZnO due to increased ROS-mediated cell injury. Adv Funct Mater 2009;19:842-52.

[57] Miura M, Gronthos S, Zhao M, Lu B, Fisher LW, Robey PG, et al. SHED: stem cells from human exfoliated deciduous teeth. Proc Natl Acad Sci USA 2003;100:5807-12.

[58] Liu W, Su P, Chen S, Wang N, Ma Y, Liu Y, et al. Synthesis of $\mathrm{TiO}_{2}$ nanotubes with $\mathrm{ZnO}$ nanoparticles to achieve antibacterial properties and stem cell compatibility. Nanoscale 2014;6:9050-62. 